\title{
Segurança do trabalho no beneficiamento do RCC inerte
}

\author{
Safety in the workplace in beneficiation of CDW inert
}

\begin{abstract}
Maria da Paz Medeiros Fernandes
Luiz Carlos Pinto da Silva Filho

\section{Resumo}

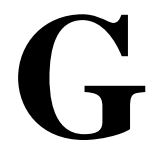

rande quantidade de resíduos da construção civil (RCCs) é gerada nas atividades de construção. O desafio é reduzir esse volume na geração. Para induzir essa mudança na gestão desses resíduos, o Conselho Nacional do Meio Ambiente (Conama) publicou as Resoluções $n^{\circ}$ 307/2002, 348/2004, 431/2011 e 448/2012. Entretanto, aspectos relativos à Segurança e Saúde do Trabalho (SST) na manipulação e processamento dos RCCs ainda são olvidados. Com o objetivo de contribuir para enfatizar essa questão e ajudar a superar essa lacuna, esta pesquisa utilizou como método de investigação o estudo de caso através do uso de casos múltiplos, tendo como unidades de análise as três áreas de reciclagem (ARs) de Belo Horizonte, municipalidade que apresenta um dos melhores registros na gestão dos RCCs no Brasil. O levantamento de dados foi realizado de 2009 até 2014 através de documentação indireta, com coleta direta de dados em 2011. Após a análise das evidências coletadas, observa-se que elas corroboraram a proposição teórica inicial, de que as ARs estão sujeitas a condições de SST que necessitam ser estudadas, aprimoradas e mais bem controladas. Assim, os resultados podem orientar as propostas de melhorias no gerenciamento dos RCCs em outros municípios, principalmente no que se refere à SST.
\end{abstract}

Maria da Paz Medeiros Fernandes

Instituto Federal de Educação, Ciência e Tecnologia da Paraíba João Pessoa - PB - Brasil

Luiz Carlos Pinto da Silva Filho Universidade Federal do Rio Grande

do Sul

Porto Alegre - RS - Brasil

Recebido em 07/06/14 Aceito em 22/03/15
Palavras-chaves: Resíduos da construção civil. Saúde e Segurança do Trabalho. Gestão.

\section{Abstract}

A large quantity of construction and demolition waste $(C D W)$ is generated during building construction and other related activities. The challenge is to reduce these volumes. To induce change, the national environmental council (CONAMA) of Brazil has published resolutions 307/02, 384/04, 431/11 and 448/12. Nonetheless, aspects related to Health and Safety in the handling of CDW have been oversighted. With the aim of contributing to overcome this gap this research used a case study approach to analyse multiple examples of recycling areas in Belo Horizonte, municipality that has the best track record in management of $C D W$ in the country. The data collection done between 2009 and 2014 through the analysis of indirect sources, A direct data collection exercise was done in 2011. After the analysis of the evidence registered, it was confirmed the initial hypothesis that $H \& S$ setups in CDW recycling areas need to be better studied, improved and controlled. The expectation is that the results presented in this paper can help subside proposals for improvement in $C D W$ management schemes in other municipalities, especially regarding $H \& S$ issues.

Keywords: Construction and demolition waste. Health and Safety in the Workplace. Management. 


\section{Introdução}

Os resíduos da construção civil (RCCs) são materiais provenientes de serviços de demolição, reforma e construção de obras da engenharia civil, os quais constituem, nas áreas urbanas, algo entre $40 \%$ e $70 \%$ do total de resíduos sólidos urbanos (PINTO, 1999; CARNEIRO, 2001; PINTO et al., 2005), a depender do crescimento imobiliário do município.

Esse alto volume de resíduos, muitas vezes, é descartado clandestinamente, o que causa impactos ambientais, sanitários, econômicos e de planejamento no ambiente urbano (SCHNEIDER; PHILIPPI, 2004; LINHARES; FERREIRA; RITTER, 2007; DE MELO, 2009; TESSARO; SÁ; SCREMIN, 2012; GUERRERO; MAAS; HOGLAND, 2013), quando poderiam ser, em sua maioria, reciclados.

No Brasil, visando regulamentar a gestão diferenciada dos resíduos, foram instituídas a Resolução $n^{\circ} 307$ do Conselho Nacional do Meio Ambiente (Conama) (CONSELHO..., 2002) e a Política Nacional de Resíduos Sólidos (PNRS), Lei $\mathrm{n}^{\circ} 12.305$ (BRASIL, 2010a), regulamentada pelo Decreto 7.404/2010 (BRASIL, 2010b).

A Resolução $n^{\circ} 307$ (CONSELHO, 2002) estabelece diretrizes, critérios e procedimentos para a redução, o reaproveitamento e a reciclagem dos RCCs, dividindo-os em quatro classes:

(a) A: inertes passíveis de reaproveitamento e/ou reciclagem como agregados;

(b) B: recicláveis;

(c) $\mathrm{C}$ : inviáveis de reciclagem; e

(d) D: resíduos perigosos

Determina que para o RCC ainda inviável de reciclagem e/ou reaproveitamento sejam utilizadas técnicas de destinação e de disposição (para os rejeitos) ambientalmente adequadas, sobretudo em relação aos resíduos perigosos, através de transportadoras e áreas de destino licenciadas para esse fim.

Ao longo do tempo, a Resolução n 307 foi modificada através da Resolução no 348 (BRASIL, 2004), que colocou o amianto como resíduo perigoso; da Resolução no 431 (BRASIL, 2011), que alocou o gesso como resíduo reciclável classe B; e da Resolução n ${ }^{\circ} 448$ (BRASIL, 2012), que adequou a Resolução $\mathrm{n}^{\mathrm{o}} 307$ às exigências da PNRS (CONSELHO..., 2010).

A busca pela redução da geração e pela reutilização e reciclagem dos resíduos gerados, incorporada na legislação brasileira, é uma meta mundial (POON et al., 2004; TAM; TAM, 2006;
ALDANA; SERPELL, 2012; YEHERYIS et al., 2013; CALVO; CANDAMIO; CORTI, 2014). Isso ocorre a fim de evitar os desperdícios e salvaguardar os recursos naturais e o meio ambiente para as gerações futuras, mediante a promoção de um desenvolvimento sustentável.

Em relação à reciclagem dos RCCs, a legislação brasileira possui como laboratório experiências municipais pioneiras da década de 1990. Especialmente a partir dos anos 2000, com a Resolução no 307 (CONSELHO..., 2002), o RCC classe A vem sendo beneficiado em algumas municipalidades em áreas de reciclagem (ARs) (BRASIL, 2012).

Geralmente, as ARs no Brasil possuem equipamentos básicos como britador (de martelos ou de mandíbulas), esteira transportadora, peneirador e pá carregadeira, com os quais é possível beneficiar o RCC classe A (CONSELHO..., 2002) por britagem e/ou peneiramento, e produzir agregados reciclados (COUTO NETO, 2007; REMBISKI, 2012; FERNANDES, 2013).

De acordo com Silva (2006), as ARs devem buscar a qualidade do processo, o respeito e a proteção ao meio ambiente, e a melhoria das condições de saúde e segurança do trabalho (SST). A integração dessas três áreas pode proporcionar, além da qualidade do produto e do cumprimento das legislações ambiental e de SST, a redução de custos e o aumento da produtividade (KOEHN; DATTA, 2003).

Em relação à SST, Pinto e Silva (2006), em trabalho desenvolvido visando à identificação e medição dos contaminantes ambientais em ARs brasileiras, comprovaram que, entre os riscos ambientais presentes nessas áreas, evidenciavamse a poeira (risco químico associado a várias doenças e a danos ao sistema respiratório e pulmões) e o ruído (risco físico, que pode causar dano físico, mental e psicológico ao trabalhador e distúrbio à comunidade do entorno).

Esse estudo pioneiro foi promovido pela Fundação Jorge Duprat Figueiredo de Segurança e Medicina do Trabalho (Fundacentro), organização de pesquisa vinculada ao Ministério do Trabalho. Ele identificou que as principais fontes de ruído em ARs brasileiras são o processo de britagem dos resíduos e a movimentação de veículos (caminhões e pá carregadeira, que circulam por toda a área do processo).

Em uma das medições ambientais da pesquisa da Fundacentro (PINTO; SILVA, 2006), o operador 
da pá carregadeira chegou a estar exposto a uma dose de ruído de $4.046,3 \%$, a qual ultrapassa várias vezes o máximo permitido de $100 \%$ (critério de referência de nível de ruído de $85 \mathrm{~dB}$ (A) para $8 \mathrm{~h}$ de exposição).

Em relação à poeira, as maiores fontes geradoras nas ARs são a operação de britagem, a movimentação da pá carregadeira, a movimentação das esteiras transportadoras abertas e o vento, que espalha o material (estocado em montes no chão) sem proteção, o que gera altas concentrações de poeira no ar e grandes variações em sua concentração (PINTO, 2005).

A principal composição encontrada na poeira das ARs é sílica livre cristalizada ou quartzo, devido ao fato de que muitos dos materiais usados nas obras de construção civil possuem em sua composição tais materiais (SANTOS; PINTO, 2008).

Nesse sentido, ressalta-se que o risco químico da poeira também é elevado nos canteiros de obra, o que pode ser minorado com o uso de construção modular ou pré-fabricado, que reduz significativamente a geração dos RCCs (POON et al., 2004). Essa redução, segundo Jaillon, Poon e Chiang (2009), é de cerca de $50 \%$ em relação à construção convencional. Outras medidas preventivas, como o uso de materiais mais duráveis e reutilizáveis e o planejamento e organização do trabalho, também reduzem os RCCs (FORMOSO et al., 2002).

A redução dos RCCs na geração é o objetivo prioritário da gestão de resíduos (CONSELHO..., 2002; BRASIL, 2010, 2012; FERNANDES, 2013) e primordial para conseguir-se a almejada produção enxuta, que também contribui para melhorar as condições de SST na construção civil (FORMOSO et al., 2002). Deve ter um enfoque que começa desde a etapa inicial de projeto de construções (DING, 2008), em uma abordagem holística, que integre todas as etapas do ciclo de vida dos materiais usados na construção civil (SHEN et al., 2007).

Para tanto, desde a fase de projeto de novas construções e de reformas é crucial ter como critério na escolha de materiais que eles sejam ambientalmente sustentáveis (YEHERYIS et al., 2013). Isso favorece o meio ambiente e a SST, tanto dos que labutam na obra quanto dos que vierem a manipular seus resíduos.

Além da escolha de materiais sustentáveis, outro ponto capital que começa nos canteiros de obra e reverbera nas ARs é a necessidade de uma rotina de segregação dos diferentes tipos de RCCs no exato momento de sua geração (POON; Yu; NG,
2001). Isso previne a contaminação dos resíduos e do meio ambiente, promove a qualidade do agregado reciclado produzido e favorece o ambiente de trabalho nas ARs e na região do entorno.

Segundo Pinto (2005), também pode existir poeira metálica nas ARs e fibras de asbesto (amianto), material que causa asbestose (doença grave e irreversível) e câncer de pulmão. Esses contaminantes podem ser evitados com cuidados específicos de segregação e proteção ao meio ambiente e aos trabalhadores, sobretudo nas reformas e demolições em que há amianto e outros materiais perigosos (CHUNG; LO, 2003).

Portanto, a reciclagem dos RCCs classe A é ambientalmente imprescindível e, por ser requerida pela legislação vigente (CONSELHO..., 2002; BRASIL, 2010a, 2012), esse procedimento se multiplicará no território nacional e envolverá grande número de trabalhadores, o que traz riscos e condições insalubres ainda pouco investigados e divulgados.

Deve-se, portanto, aprimorar a gestão dos RCCs também nos aspectos relativos à SST, a fim de preservar a saúde e a integridade física dos trabalhadores envolvidos e da própria comunidade do entorno (PINTO, 2005; PINTO; SILVA, 2006; SILVA, 2006; SANTOS; PINTO, 2008; FERNANDES, 2013).

Dessa forma, o presente estudo visa contribuir para enfatizar aspectos relativos à SST em áreas de reciclagem de RCC classe A (CONSELHO..., 2002), em especial por essa abordagem ser um aspecto crucial e ainda pouco investigado, a qual nem sequer consta entre os tópicos normalmente citados na temática de gestão desse tipo de resíduo (ALDANA; SERPELL, 2012).

Para dar suporte à investigação foi escolhida a municipalidade de Belo Horizonte, metrópole que possui 2.258.096 de habitantes (INSTITUTO..., 2010) e que tem destaque nacional, devido à continuidade de um planejamento de gestão diferenciada do RCC, iniciado em 1993.

Belo Horizonte possui três ARs públicas em funcionamento, denominadas estações de reciclagem (ERs), que foram selecionadas para a pesquisa por possuírem décadas de atividade ininterrupta em ambiente urbano e representarem, com suas diferentes áreas e equipamentos, a realidade da maioria das ARs brasileiras.

O presente artigo está estruturado em seis tópicos: a introdução apresenta o problema de pesquisa, sua importância, o objetivo da pesquisa e a estrutura do artigo; em seguida, na segunda seção, descrevese o método de pesquisa utilizado para desenvolver 
o trabalho; no terceiro tópico apresentam-se os resultados da pesquisa, com a descrição do processo produtivo nas ARs, as condições de SST observadas pelos pesquisadores e as relatadas pelos entrevistados; e na quarta parte são apresentadas as principais conclusões e sugestões para a continuidade da pesquisa.

\section{Método de investigação}

Esse estudo, que faz parte de uma pesquisa mais ampla sobre a gestão municipal dos RCCs, teve como ponto de partida a constatação de que as condições de SST nas ARs são pouco investigadas na bibliografia relativa à temática.

Isso suscitou duas teorias concorrentes relacionadas ao tópico de estudo:

(a) o estudo de caso mostrará que as ARs estão sujeitas a condições de SST que necessitam ser estudadas, aprimoradas e mais bem controladas; e

(b) o estudo de caso mostrará que as condições de SST nas ARs estão devidamente controladas e adequadas à saúde e à integridade física dos trabalhadores.

As teorias iniciais provocaram o seguinte questionamento: como são as condições de Saúde e Segurança do Trabalho nas ARs?

Para responder a esse questionamento foi utilizado o estudo de caso, que é o método adequado para essa abordagem, por se tratar de um fenômeno contemporâneo inserido na vida real e sobre o qual o investigador não tem controle sobre os eventos (YIN, 2009). A pesquisa foi realizada através do uso de casos múltiplos, para melhor investigar o fenômeno e tornar mais robusta a generalização analítica (STAKE, 2000; YIN, 2009).

Foram selecionadas como unidades de análise as três ARs públicas de Belo Horizonte, devido à similaridade com as demais ARs fixas usadas no Brasil e ao fato de funcionarem continuamente desde a inauguração. Destaca-se que esse é um município pioneiro na gestão diferenciada dos RCCs.

As três ARs são municipais. Duas estão inseridas dentro dos bairros, Estoril (que funciona desde 1995) e Pampulha (que funciona desde 1996), e possuem equipamentos básicos. A terceira localiza-se na BR-040 e produz agregados reciclados mais diversificados, funcionando desde 2006 na Central de Tratamento de Resíduos Sólidos (CTRS 040), que é um complexo integrado para gestão de resíduos sólidos urbanos. Essas ARs estão inseridas no contexto da realidade dos municípios, dos trabalhadores e da sociedade do entorno.
Para desenvolver a pesquisa foi elaborado o protocolo do estudo com uma visão geral do projeto e procedimentos de campo determinando como e quais dados devem ser coletados, e as estratégias de análise desses dados. Essa preparação prévia para coleta direta de dados em campo visa manter o rigor metodológico (YIN, 2009).

A coleta dos dados na pesquisa de campo é feita nas condições naturais em que os fenômenos ocorrem, sendo assim diretamente observados, sem intervenção e manuseio por parte do pesquisador (SEVERINO, 2007).

Visando à validade do constructo, a fim de garantir a qualidade do projeto de pesquisa (YIN, 2009), a coleta de dados utilizou fontes múltiplas de evidências, e foi estabelecido seu encadeamento.

As fontes de evidências foram: documentação indireta (bibliografia, documentos da empresa e jornais) e coleta direta de dados (entrevistas, fotografias e observação direta).

Como o presente artigo decorre de uma pesquisa mais ampla sobre a problemática da gestão municipal dos RCCs, as perguntas relativas às condições de SST nas ARs estão inseridas dentro de dois modelos de entrevistas semiestruturadas sobre a gestão dos RCCs.

Um modelo foi aplicado aos gestores das ARs pesquisadas, e o outro modelo foi aplicado aos trabalhadores operacionais, selecionados aleatoriamente durante a execução de suas atividades, tendo-se disponibilizado a participar da pesquisa e a responder a entrevista os gestores das ARs e alguns trabalhadores, conforme explicitado a seguir.

Participaram voluntariamente da pesquisa cinco trabalhadores do total de quinze em Estoril, cinco trabalhadores do total de treze em Pampulha, e cinco do total de vinte trabalhadores na BR-040. Todos eram operacionais e multitarefa, atuando desde a inspeção visual inicial, passando pela triagem manual no pátio até a britagem e produção final dos agregados. Tanto os trabalhadores operacionais quanto os gerentes são do sexo masculino.

$\mathrm{Na}$ entrevista aplicada aos gestores das ARs, em relação à SST, foram abordados os seguintes itens:

(a) proteção coletiva contra vibração, ruído, radiação solar, aerodispersoides (partículas dispersas no ar), piso escorregadio e em desnível, umidade, outros;

(b) medidas em relação aos riscos ergonômicos;

(c) treinamento e capacitação; 
(d) equipe para primeiros socorros;

(e) medidas para prevenção e combate a incêndio; $\mathrm{e}$

(f) equipamentos de proteção individual (EPIs) utilizados.

$\mathrm{Na}$ entrevista aplicada aos trabalhadores foram abordadas questões sobre:

(a) equipamentos e materiais disponibilizados e utilizados;

(b) dores e agravos à saúde;

(c) satisfação e motivação;

(d) relato de acidentes do trabalho ocorridos;

(e) mudanças requeridas na atividade; $\mathrm{e}$

(f) sugestões de melhoria para tornar esse ambiente mais eficiente e saudável.

O levantamento de dados foi realizado de 2009 até 2014 através de documentação indireta, tendo sido feita em 2011 a coleta direta de dados por meio da observação sistemática com documentação fotográfica e da aplicação das entrevistas.

Nesse sentido, a experiência de duas décadas na área de SST de um dos pesquisadores foi fator primordial para a elaboração das entrevistas e do roteiro de observação que pudessem capturar evidências relevantes (YIN, 2009). Esse roteiro foi baseado na tipologia de riscos usada no mapeamento de riscos em SST.

Tanto na elaboração quanto na aplicação das entrevistas buscou-se evitar possíveis influências do investigador nas respostas dos entrevistados. A preparação para a coleta direta de dados levou três meses, inclusive com o envio prévio dos formulários de entrevistas para a análise por parte da Superintendência de Limpeza Urbana (SLU).

Durante a coleta direta de dados foi permitida a ampla utilização de documentação fotográfica, entretanto a gravação das entrevistas foi abandonada, por intimidar os entrevistados. As respostas dos trabalhadores possibilitaram a geração de tabelas com percentuais que expressam a percepção deles em relação aos riscos e aos agravos a saúde.

Após a coleta, as evidências foram recombinadas tendo em vista as proposições teóricas iniciais do estudo de caso. Foi feita a análise cruzada com o uso de uma estratégia analítica para análise dos resultados a fim de identificar se existia uma lógica que unia os dados às proposições iniciais, de forma a permitir a generalização analítica dos resultados e sua replicação.

\section{Resultados e discussão}

Belo Horizonte possui três ARs municipais. Nessas áreas pode ser entregue gratuitamente RCC classe A (aqueles reutilizáveis ou recicláveis como agregados) com contaminação máxima de $10 \%$.

\section{Processo produtivo nas ARs estudadas}

Nesse item é explicitado o processo produtivo nas ARs, a fim de elucidar as tarefas cotidianamente desenvolvidas pelos trabalhadores e facilitar a visualização dos riscos e dos agravos à saúde por etapa de trabalho.

Ao chegar nas ARs, o transportador de resíduos entrega o Controle de Transporte de Resíduos (CTR) na portaria, e os RCCs são visualmente inspecionados por um trabalhador. Depois isso, o resíduo passa por uma chuveirada, a fim de ficar úmido e minimizar a poeira ao ser descarregado no pátio de triagem. Entretanto, foi observado que a chuveirada é ineficiente, pois há grande formação de poeira nessa operação, a qual incide sobre os trabalhadores.

No pátio de triagem ocorre nova inspeção visual, feita por duplas de labutadores, e caso seja constatada irregularidade de contaminação o resíduo será devolvido ao caçambeiro que o trouxe.

Em seguida, o material aceito passa pela triagem manual, uma tarefa demorada e desenvolvida de maneira penosa, a céu aberto, sob forte radiação solar, sujeita a intempéries e com posturas inadequadas. No pátio de triagem também são quebrados manualmente com marretas os RCCs volumosos, possibilitando a britagem posterior. Essa tarefa acarreta riscos de acidentes e grande desgaste aos trabalhadores.

Após a triagem nas ARs de Estoril e da Pampulha, o RCC selecionado é transportado por pá carregadeira até o alimentador vibratório. Esse transporte ocasiona grande formação de poeira e ruído, riscos ambientais que afetam os trabalhadores e também o ambiente do entorno. Os riscos à sociedade são amenizados pela presença da cerca-verde circundando as três ARs.

$\mathrm{O}$ alimentador vibratório nutre o britador fixo de impacto (martelo que produz o rachão nas duas ARs). Nessa etapa o principal risco é o ruído, o qual é amenizado pela manta acústica colocada nos equipamentos de britagem. Então o agregado produzido é transportado por correia, com separador magnético, para tirar possíveis resíduos metálicos. Nas correias ocorre formação de poeira 
devido à incidência direta do vento sobre os agregados.

Em seguida o agregado é armazenado no pátio na forma de pilhas, o que novamente gera poeira, devido à deposição por gravidade e à incidência direta do vento sobre os agregados.

$\mathrm{Na}$ AR da BR-040 os equipamentos possibilitam a produção de vários tipos de agregados reciclados além do rachão. Inicialmente, após passar pelo pátio de triagem, o RCC aceito é colocado por pá carregadeira no alimentador vibratório que nutre a grelha vibratória, onde é feito o prébeneficiamento (peneiramento) do RCC, o que resulta em bica corrida. Há grande formação de poeira, além de ruído e vibração.

Depois isso os resíduos passam pelo britador de mandíbula, que tem a possibilidade de regular o tamanho máximo do agregado requerido. Nessa etapa o principal risco é o ruído, o qual é amenizado pela manta acústica colocada nos equipamentos de britagem. Depois o material britado é transportado por correias utilizando o separador magnético, a fim de retirar pequenos fragmentos de metal, sendo obtido o rachão, que poderá ser utilizado pela prefeitura ou comercializado, ou ainda ser novamente processado para a obtenção de outros agregados.

Assim, caso sejam requeridos outros agregados, o rachão é transportado na calha vibratória para o deck. Nesse transporte há formação de poeira e também de ruído. O deck possui três grelhas vibratórias, que, ao peneirarem o RCC britado, produzem brita, brita 0 , brita 1 e areia. Nessa etapa os principais riscos são ruído e vibração.

Os resíduos com diâmetro superior a $19 \mathrm{~mm}$ que restaram no deck são transportados por correia para serem rebritados no cone de britagem. Um sistema de esteiras transporta esses diferentes agregados produzidos, a fim de que eles sejam armazenados em pilhas de homogeneização, reduzindo a possibilidade de contaminação, aumentando a qualidade do agregado e facilitando sua comercialização, conforme mostra a Figura 1. Há a formação de poeira durante todo o processo.

\section{Condições de saúde e segurança nas ARs}

Conforme elucidado na descrição do processo produtivo, vários riscos foram observados nas ARs. De acordo com as entrevistas aplicadas aos gestores das ARs, a identificação dos riscos nessas áreas é realizada por uma equipe especializada da prefeitura, que busca sempre minorá-los com medidas de controle e com a conscientização dos trabalhadores. Também estão presentes equipamentos básicos de combate a incêndio e material para curativos.

Nesse sentido, ações relacionadas à SST como umidificar o material para diminuir a formação de poeira, utilizar manta acústica nos equipamentos para redução do ruído e fornecer equipamentos de proteção individual (EPIs) vêm sendo realizadas nas ARs de Belo Horizonte, conforme entrevistas aplicadas aos gestores e aos trabalhadores e observação direta, diferentemente do que ocorre em algumas ARs brasileiras, que ainda não atentaram sequer para as condutas básicas de proteção dos trabalhadores (PINTO, 2005).

De fato foi observado que os trabalhadores das ARs estudadas utilizam boné, luvas, botas e fardamento completo (calça comprida com blusa: sem manga; manga três quartos; manga comprida). São usadas máscaras em todas as operações e abafadores nas atividades de beneficiamento. Todos os trabalhadores disseram compreender a necessidade dos equipamentos de proteção e que são encorajados a detectar e a informar situações de risco durante a realização das tarefas.

Entretanto, existem medidas que precisam ser aprimoradas. A Figura 2 mostra a estratégia defensiva de alguns trabalhadores ao buscar maior proteção contra a forte radiação solar, enquanto outros usam apenas boné e não cobrem os braços. Assim, deve ser recomendada a manga comprida e a troca do boné por uma proteção de cabeça e pescoço, devido à forte radiação não ionizante solar no pátio de triagem e nas demais atividades operacionais a céu aberto das ARs.

Também há a necessidade de melhorias no pátio de triagem devido à penosidade do trabalho. A Figura 3 mostra posturas inadequadas na realização da tarefa e no levantamento e transporte de carga, além de elevada poeira, decorrente das descargas dos RCCs.

Na AR da BR-040, além dos postos de trabalho presentes nas outras duas ARs, há trabalhadores na alimentação do britador, na correia que conduz bica corrida, na correia que transporta rachão e nas correias da saída do deck para o cone de britagem. Os postos de trabalho nas correias de beneficiamento possuem proteção de lona ou guarda-sol, a fim de minorar a radiação não ionizante solar nos trabalhadores, conforme mostra a Figura 4.

Em relação às dores e aos agravos à saúde relatados pelos trabalhadores entrevistados nas ARs, a Figura 5 apresenta o resultado coletado. 
Figura 1 - Pátio de operação e armazenamento da AR da BR-040

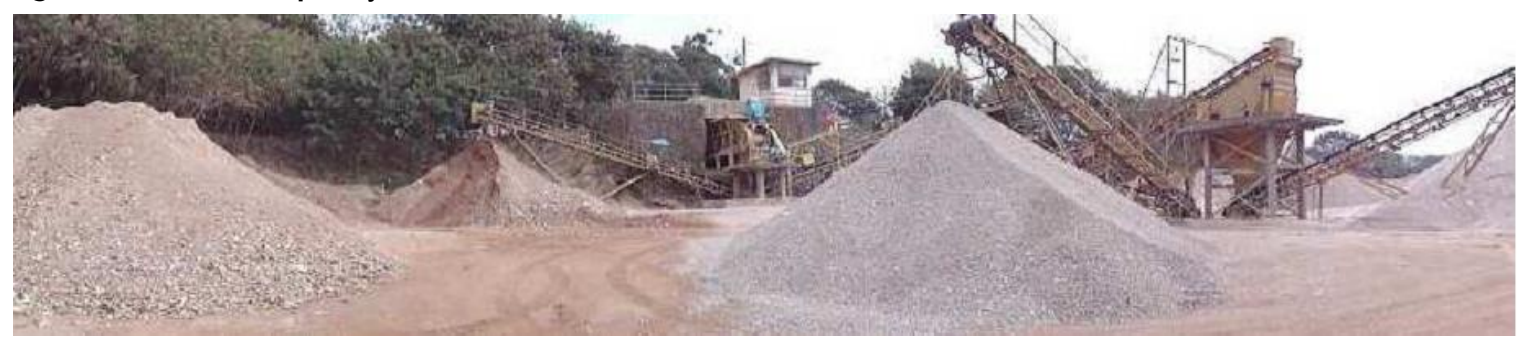

Figura 2 - Proteção individual dos trabalhadores nas ARs
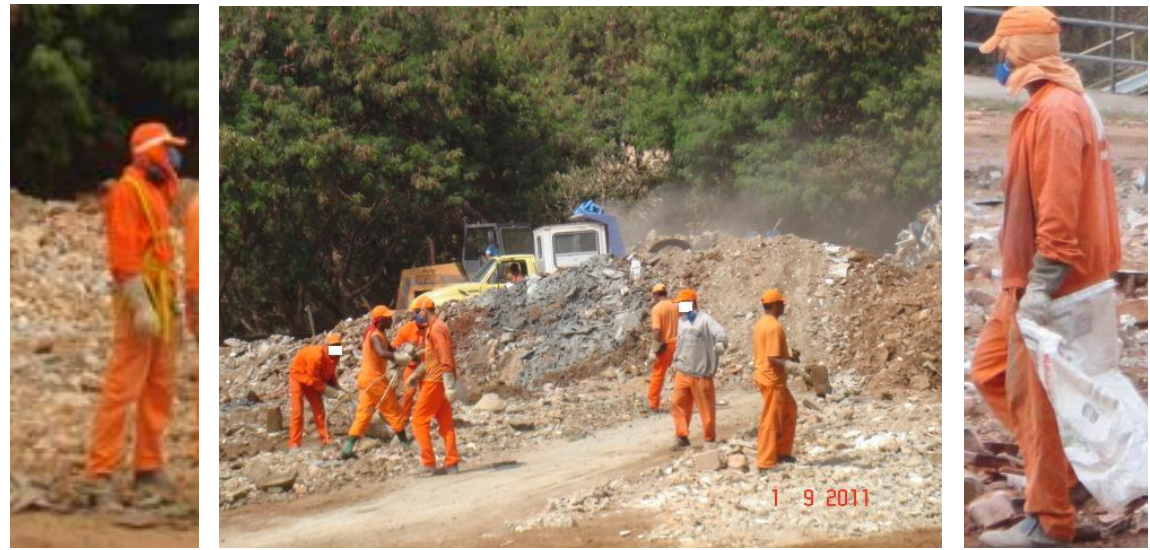

Figura 3 - Situações de riscos durante a triagem dos resíduos nas Ars

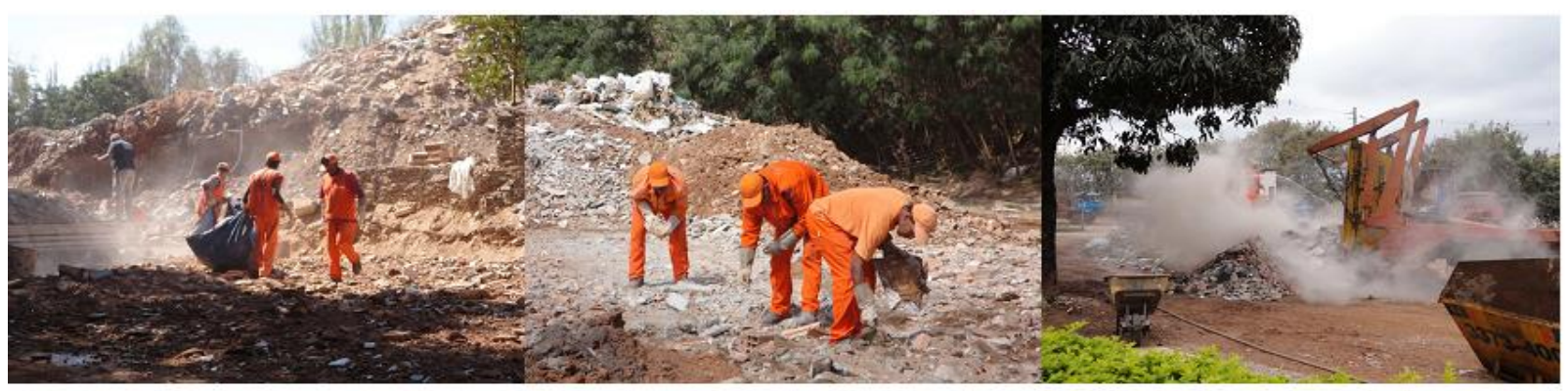

Figura 4 - 0 trabalho nas correias de beneficiamento da AR na BR-040
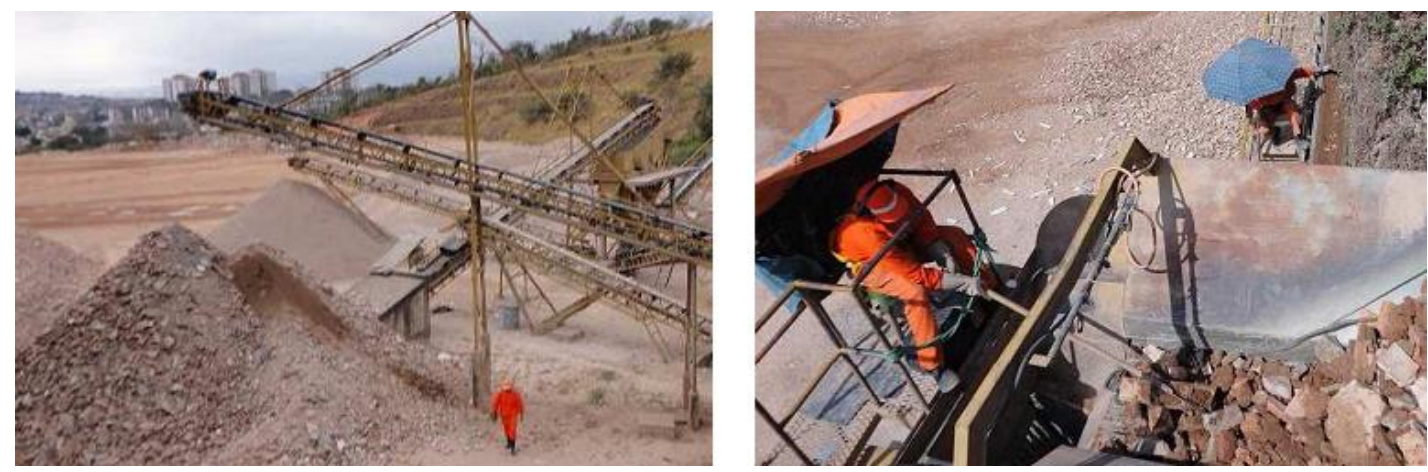
No que diz respeito à satisfação e à motivação com o trabalho, a Figura 6 apresenta os percentuais por AR conforme dados coletados nas entrevistas.

$\mathrm{O}$ alto índice de satisfação em Estoril não surpreende, pois essa AR possui bastante verde, mesas para descanso e refeição, e sala de reunião circular sob as árvores, ou seja, recursos paisagísticos e sociais que melhoram o ambiente de trabalho, conforme mostra a Figura 7. Na entrevista esses elementos foram apontados por $100 \%$ dos trabalhadores como motivacionais.

Figura 5 - Agravos à saúde nas ARs conforme entrevista

\section{Agravos a saúde nas ARs}

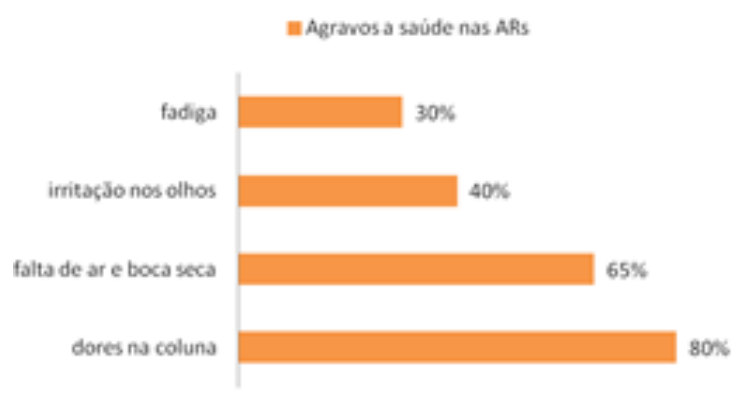

Figura 6 - Satisfação dos trabalhadores nas Ars

Satisfação dos trabalhadores nas ARs

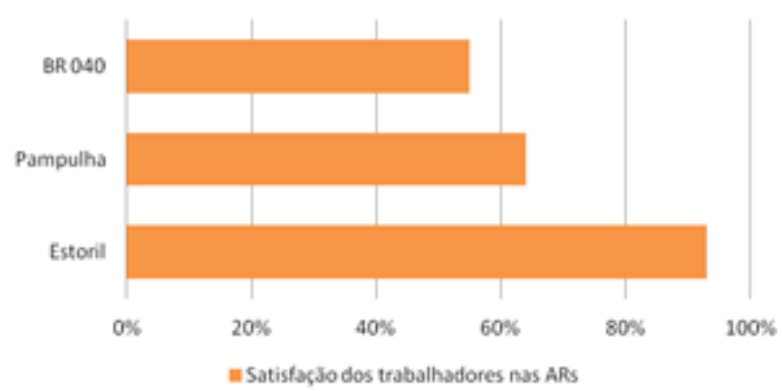

Figura 7 - Recursos paisagísticos e de relaxamento na AR de Estoril

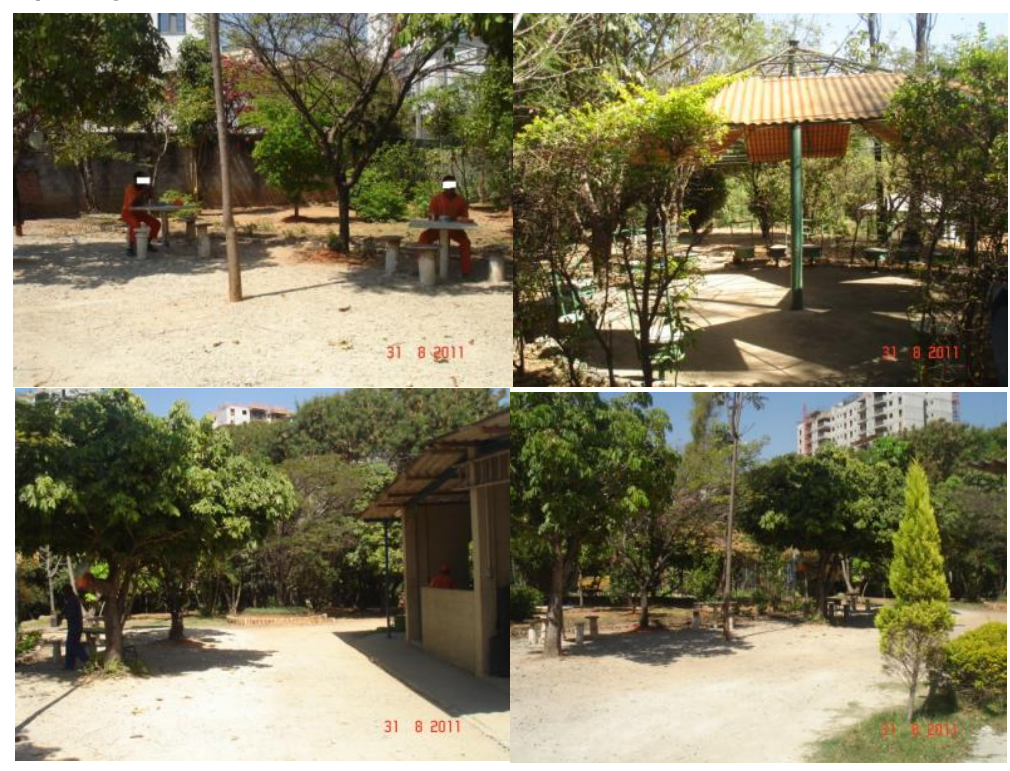

120 Fernandes, M. da P. M.; Silva Filho, L. C. P. da. 
Outro fator indicado como motivacional pelos trabalhadores entrevistados nas três ARs foi a frequência de visitas escolares, que, segundo os trabalhadores, dignificam e valorizam sua atividade, pois "lembram de seus filhos e sentem orgulho do que fazem", "se eles (referindo-se aos professores e/ou guias) vêm mostrar isso nesse calorão, é porque isso tem muito valor".

Quanto aos acidentes do trabalho ocorridos nas ARs, os trabalhadores entrevistados relataram apenas pequenos cortes e incidentes, que servem de alerta para tomarem mais cuidado ao subir nas máquinas e ao transitar pelas ARs em meio a caminhões, retroescavadeiras e demais veículos de transporte.

Em relação às mudanças requeridas na atividade $\mathrm{e}$ sugestões de melhoria para tornar esse ambiente mais eficiente e saudável, $90 \%$ dos trabalhadores operacionais entrevistados nas três ARs indicam o controle da poeira decorrente da britagem e da descarga de materiais na triagem e no armazenamento como a principal melhoria requerida. Nesse sentido, observa-se que a umidificação (chuveirada na entrada e aspersores e mangueiras no pátio) é insuficiente para debelar o problema.

Vale salientar que a poeira presente nas ARs é basicamente sílica. A American Conference of Governmental Industrial Hygienists (AMERICAN..., 2002) considera a sílica como uma substância potencialmente carcinogênica para humanos. Santos e Pinto (2008) associam a sílica, além da silicose, a outras doenças, como bronquite, tuberculose, câncer de pulmão, câncer do trato gastrointestinal, artrite reumatoide e algumas doenças crônicas.

Devido à variabilidade da composição e das dimensões das partículas de poeira, torna-se necessário um controle rigoroso dos RCCs manipulados e beneficiados nas ARs, para evitar, inclusive, outros contaminantes perigosos.

Ressalta-se que a percepção da poeira pelos trabalhadores é bastante acentuada nas ARs de Belo Horizonte, mas o ruído, que é um risco de grande incidência nas ARs brasileiras (PINTO; SILVA, 2006; SILVA, 2006), não foi lembrado pelos trabalhadores entrevistados.

Nesse sentido, pode-se supor que o uso do abafador pelos trabalhadores e a manta acústica nos equipamentos das ARs estudadas satisfaçam as exigências de proteção requeridas pelos trabalhadores para esse risco.

Deve, entretanto, ser evidenciado que o ruído, muitas vezes, vai reduzindo de forma progressiva a capacidade auditiva do trabalhador sem que este perceba, devendo haver medições ambientais e exames audiométricos periódicos para que seja evitada uma possível perda auditiva em todo e qualquer ambiente de trabalho com incidência desse risco ambiental.

Portanto, durante o processo produtivo nas ARs brasileiras estão presentes vários riscos ao ambiente e à saúde e integridade física dos trabalhadores, com elevada incidência de poeira e ruído (PINTO; SILVA, 2006; SILVA, 2006). Além desses riscos ambientais documentados na bibliografia, destaca-se a forte radiação solar e riscos ergonômicos e de acidentes com lesão, conforme verificado por observação direta.

Procedendo-se ao encadeamento das evidências coletadas, após fazer o cruzamento dos dados colhidos nas diversas fontes por documentação indireta e por documentação direta, ficou evidente que há uma lógica que une os dados às proposições iniciais e que permite a generalização analítica dos resultados e sua replicação.

Assim, podem-se elencar os riscos gerais nas atividades desenvolvidas em ARs no Brasil e as medidas de controle recomendadas para essas unidades produtivas, conforme mostra o Quadro 1.

As medidas de controle recomendadas no Quadro 1 seguem a hierarquia prevista na Norma Regulamentadora 9 (MINISTÉRIO..., 2014), que prioriza a implementação de medidas de caráter coletivo (em três níveis também hierárquicos: eliminar totalmente o risco; evitar que o risco atinja o trabalhador; minimizar o risco no ambiente de trabalho). Caso esses procedimentos coletivos sejam insuficientes, devem ser complementados por soluções de organização do trabalho e pelo uso de EPIs.

Essa hierarquia é semelhante à indicada pela European Economic Community $\left(1989^{1}\right.$ apud BLECK; WETTBERG, 2012), que pode ser memorizada como "STOPP-Principle" e prioriza a substituição e/ou a melhoria de processos e materiais, seguida por medidas técnicas, depois medidas organizacionais, ficando por último as medidas que não combatem o risco, mas apenas colocam uma proteção entre o risco e o trabalhador. Assim, tem-se como último recurso na proteção do trabalhador o uso do EPI e/ou o comportamento pessoal devido à dificuldade em mudar as condutas pessoais (BLECK; WETTBERG, 2012).

${ }^{1}$ EUROPEAN ECONOMIC COMMUNITY. Council Directive $89 / 391 /$ EEC, of 12 June 1989 on the introduction of measures to encourage improvements in the safety and health of workers at work. Official Journal of the European Communities, L 183, 29 jun. 1989. 
Quadro 1 - Riscos nas atividades desenvolvidas em ARs

\begin{tabular}{|c|c|c|c|c|}
\hline Riscos nas ARs & Fator & $\begin{array}{l}\text { Fontes de } \\
\text { evidências }\end{array}$ & $\begin{array}{l}\text { Posto de } \\
\text { trabalho }\end{array}$ & Medidas de controle recomendadas \\
\hline Riscos Físicos & $\begin{array}{l}\text { Calor, } \\
\text { Radiação não } \\
\text { ionizante solar } \\
\text { Intempéries } \\
\text { Baixa umidade } \\
\text { (sazonal) } \\
\text { Ruído e vibração }\end{array}$ & $\begin{array}{l}\text { Observação } \\
\text { Direta, } \\
\text { Entrevistas } \\
\text { Entrevistas, } \\
\text { Documentação } \\
\text { Indireta e } \\
\text { Obs. Direta } \\
\text { Documentação } \\
\text { Indireta e } \\
\text { Obs. Direta }\end{array}$ & $\begin{array}{l}\text { Todos } \\
\text { Todos } \\
\text { Todos } \\
\text { Todos } \\
\text { Britagem, pá } \\
\text { carregadeira, } \\
\text { peneiramento }\end{array}$ & $\begin{array}{l}\text { Sombreamento (árvores), umidificar } \\
\text { Sombreamento, tendas abertas removíveis, } \\
\text { chapéu de abas largas, proteção para o } \\
\text { pescoço, protetor solar, mangas e calças } \\
\text { compridas, óculos solares } \\
\text { Drenagem e uso de pedrisco reciclado no piso, } \\
\text { capa. Umidificar o ambiente e fornecer água } \\
\text { potável } \\
\text { Manta acústica no britador, nas peneiras e nas } \\
\text { esteiras, cabine com isolamento acústico nas } \\
\text { máquinas e equipamentos, protetor auricular } \\
\text { concha (abafador) }\end{array}$ \\
\hline $\begin{array}{l}\text { Riscos } \\
\text { Químicos }\end{array}$ & $\begin{array}{l}\text { Poeira, } \\
\text { Aerodispersoides } \\
\text { dos RCCs }\end{array}$ & $\begin{array}{l}\text { Documentação } \\
\text { Indireta, } \\
\text { Fotografias, } \\
\text { Obs. Direta e } \\
\text { Entrevistas }\end{array}$ & $\begin{array}{l}\text { Todos } \\
\text { Todos }\end{array}$ & $\begin{array}{l}\text { Umidificar e/ou usar agregado no solo. } \\
\text { Umidificar o RCC ao descarregar, melhorar os } \\
\text { postos de trabalho, cabine isolada na operação } \\
\text { das máquinas e equipamentos, cobrir os } \\
\text { materiais, protetor respiratório com filtro para } \\
\text { poeira de RCC, óculos de proteção }\end{array}$ \\
\hline $\begin{array}{l}\text { Riscos } \\
\text { Ergonômicos }\end{array}$ & $\begin{array}{l}\text { Posturas } \\
\text { inadequadas de } \\
\text { trabalho, } \\
\text { Esforço físico } \\
\text { intenso, } \\
\text { Levantamento e } \\
\text { transporte de } \\
\text { cargas }\end{array}$ & $\begin{array}{l}\text { Obs. Direta, } \\
\text { Fotografias e } \\
\text { Entrevistas }\end{array}$ & $\begin{array}{l}\text { Todos } \\
\text { Triagem } \\
\text { Triagem }\end{array}$ & $\begin{array}{l}\text { Melhorar o posto de trabalho. Treinamento e } \\
\text { ginástica laboral } \\
\text { Aprimorar o posto de trabalho e treinamento } \\
\text { Melhorar o posto de trabalho e treinamento }\end{array}$ \\
\hline $\begin{array}{l}\text { Riscos de } \\
\text { acidentes }\end{array}$ & $\begin{array}{l}\text { Atropelamento, } \\
\text { pancadas e queda } \\
\text { Piso molhado e } \\
\text { escorregadio } \\
\text { Cortes e furadas } \\
\text { na manipulação } \\
\text { dos resíduos }\end{array}$ & $\begin{array}{l}\text { Obs. Direta e } \\
\text { Entrevistas } \\
\text { Obs. Direta, } \\
\text { Fotografias e } \\
\text { Entrevistas }\end{array}$ & $\begin{array}{l}\text { Britagem, } \\
\text { triagem nas } \\
\text { esteiras } \\
\text { Todos } \\
\text { Todos }\end{array}$ & $\begin{array}{l}\text { Plataforma com guarda-corpo e alças de } \\
\text { segurança, treinamento laboral, colete } \\
\text { refletivo, solado antiderrapante, cinto de } \\
\text { segurança } \\
\text { Drenagem superficial, treinamento laboral e } \\
\text { botas impermeáveis e antiderrapantes } \\
\text { Melhorar o posto de trabalho e usar luvas } \\
\text { específicas para RCC }\end{array}$ \\
\hline $\begin{array}{l}\text { Riscos } \\
\text { Biológicos }\end{array}$ & $\begin{array}{l}\text { Sanitário e água } \\
\text { para beber }\end{array}$ & $\begin{array}{l}\text { Obs. Direta e } \\
\text { Documentação } \\
\text { indireta }\end{array}$ & Todos & $\begin{array}{l}\text { Higienização preventiva e contínua dos } \\
\text { sanitários } \\
\text { Fornecimento de água potável em local } \\
\text { protegido }\end{array}$ \\
\hline
\end{tabular}

Vale ressaltar que medidas de controle efetivas de SST necessitam ser aprimoradas no cotidiano da realização da tarefa. Isso requer um profundo conhecimento dos riscos e dos métodos de trabalho (BLECK; WETTBERG, 2012).

Entretanto, algumas medidas paliativas podem ser utilizadas de imediato, como usar tendas removíveis (estilo praia sem laterais) no pátio de triagem, a fim de minorar a radiação solar, deixar a lona sobre as caçambas e presa nos ganchos traseiros ao descarregar os resíduos, cobrir os RCCs e os agregados reciclados, a fim de reduzir por abafamento parte da dispersão da poeira, e a utilização de carrinho de mão ou recipientes com rodas para transporte dos resíduos catados na triagem.

Como medida ambiental e econômica deve ser feita a captação e armazenamento da água das chuvas para umidificar o solo e os RCCs nas atividades que geram muito poeira, devendo-se investir em drenagem superficial nas ARs nos meses chuvosos e na umidificação constante dos resíduos, e no uso de pedrisco reciclado no solo (nas vias de trânsito de veículos), para evitar a alta incidência de poeira.

Ainda em relação ao ruído e à poeira, o estudo da Fundacentro (PINTO; SILVA, 2006) recomenda nas ARs em geral a utilização de cabine enclausurada à prova de ruído e com ar condicionado, tanto para o operador do britador quanto para o da pá carregadeira, e o enclausuramento das esteiras transportadoras e das peneiras.

Em relação às ARs brasileiras também se destaca a necessidade da implementação do Programa de Prevenção de Riscos Ambientais (PPRA), estabelecido pela Norma Regulamentadora NR 9 (MINISTÉRIO..., 2014), e o do Programa de 
Controle Médico de Saúde Ocupacional (PCMSO), estabelecido pela NR 7 (MINISTÉRIO..., 2015).

Recomenda-se, ainda, o estabelecimento de parcerias com instituições de ensino e pesquisa e com sindicatos da construção civil para a realização de cursos de capacitação com conteúdos relacionados às questões ambientais e de SST para os trabalhadores, e de pesquisas aplicadas que visem ao aprimoramento dos métodos e dos postos de trabalho em ARs.

\section{Conclusão}

Após a análise das evidências coletadas, observase que elas corroboram a proposição teórica inicial de que as ARs estão sujeitas a condições de SST que necessitam ser estudadas, aprimoradas e mais bem controladas, a ponto de permitir a generalização da teoria inicial proposta e sua replicação.

Dessa forma, a problemática e as recomendações apresentadas neste artigo poderão servir de base para ARs públicas e privadas de diferentes municipalidades, inclusive para as ARs móveis que executam o beneficiamento nos canteiros de obras.

O estudo foi significativo por enfatizar as questões relativas à SST em ARs, a fim de motivar o debate dessa temática e de contribuir para o avanço cientifico dessa área relevante para o desenvolvimento sustentável do planeta. Também, ao apresentar riscos laborais característicos dessa atividade, contribui para promover as condições de trabalho e o controle dos riscos.

Lembra-se que as condições de salubridade em ARs interferem na saúde e na qualidade de vida das pessoas que residem no entorno, na dos grandes e dos pequenos transportadores de RCCs, na da sociedade em geral e, sobretudo, na dos que lá laboram. Por isso, necessita-se de um aprimoramento dos postos de trabalho e de medidas de controle e condutas preventivas eficazes.

Durante esta pesquisa não foi feita a avaliação quantitativa dos contaminantes ambientais. Também não foi objeto do estudo a implantação das medidas de controle e de prevenção discutidas no artigo, tópicos para outras abordagens.

Assim, para a continuidade da pesquisa destacamse como temas: a análise ergonômica do trabalho; a avaliação dos contaminantes ambientais; o aprimoramento de máquinas e equipamentos, a fim de reduzir os riscos ambientais e os riscos à integridade física dos trabalhadores; e o aperfeiçoamento dos métodos de trabalho e do processo produtivo, com vistas à integração entre a SST, o meio ambiente e a qualidade dos agregados produzidos.

Enfatiza-se que o aprimoramento das condições de trabalho nas ARs é crucial, pois essa atividade produtiva é nova e amplamente incentivada pela legislação ambiental vigente no Brasil. Tal atividade deve ser profundamente avaliada e estudada na academia, devido a sua importância ambiental, sanitária e social, e devido às condições de trabalho dos que lá laboram e que necessitam ter asseguradas a saúde e a integridade física.

\section{Referências}

ALDANA, J. C.; SERPELL, A. Topics and Tendencies of Construction and Demolition Waste: a meta-analysis. Revista de la

Construcción, v. 12, n. 22, p. 4-16, 2012.

AMERICAN CONFERENCE OF GOVERNMENTAL INDUSTRIAL

HYGIENISTS. Threshold Limit Values for Chemical Substances and Physical Agents and Biological Exposure Indices. Cincinnati, $\mathrm{OH}$ : ACGIH, 2002.

BLECK, D.; WETTBERG, W. Waste Colletion in Developing Countries: tackling occupational safety and helth hazards at their source. Journal of Waste Management, v. 32, n. 11, p. 2009-2017, 2012.

BRASIL. Decreto 7.404, que regulamenta a Lei $\mathrm{n}^{\circ}$ 12.305, de 2 de agosto de 2010, que institui a Política Nacional de Resíduos Sólidos, cria o Comitê Interministerial da Política Nacional de Resíduos Sólidos e o Comitê Orientador para a Implantação dos Sistemas de Logística Reversa, e dá outras providências. Diário Oficial da República Federativa do Brasil, Brasília, DF, 23 de dezembro de 2010b.

BRASIL. Lei 12.305, que institui a Política Nacional de Resíduos Sólidos, altera a Lei 9.605/98 e dá outras providências. Diário Oficial da República Federativa do Brasil, Brasília, DF, 21 de agosto de 2010a.

BRASIL. Resolução CONAMA no 431, que altera o art. $3^{\circ}$ da Resolução CONAMA n ${ }^{\circ} .307$, de 5 de julho de 2002, estabelecendo nova classificação para o gesso. Diário Oficial da República Federativa do Brasil, Brasília, DF, 25 de maio de 2011. 
BRASIL. Resolução CONAMA n ${ }^{\circ} 448$, que altera os arts. $2^{\circ} .4^{\circ} .5^{\circ} .6^{\circ} .8^{\circ} .9^{\circ} .10^{\circ} .11^{\circ}$ da Resolução $\mathrm{n}^{\circ} 307$, de 5 de julho de 2002, do Conselho Nacional do Meio Ambiente- CONAMA. Diário Oficial da República Federativa do Brasil, Brasília, DF, 2012.

BRASIL. Resolução CONAMA ño. 348, de 16 de agosto de 2004, que altera a Resolução CONAMA $\mathrm{n}^{\circ} 307$, de 5 de julho de 2002, incluindo o amianto na classe de resíduos perigosos. Diário Oficial da República Federativa do Brasil, Brasília, DF, 2004.

CALVO, N.; CANDAMIO, L. V.; CORTI, I. N. A Dynamic Model for Construction and Demolition (C\&D) Waste Management in Spain: driving policies based on economic incentives and tax penalties. Journal Sustainability, v. 6, p. 416435, 2014.

CARNEIRO, A. P. Características do Entulho e do Agregado Reciclado. Salvador: EDUFBA, Caixa Econômica Federal, 2001. cap. 5, p. 144187. Projeto Entulho Bom.

CHUNG, S. S.; LO, C. W. H. Evaluating Sustainability in Waste Management: the case of construction and demolition, chemical and clinical wastes in Hong Kong. Resources, Conservation and Recycling, v. 37, n. 2, p. 119-145, 2003.

CONSELHO NACIONAL DO MEIO

AMBIENTE. Resolução n ${ }^{\circ}$ 307, de 05 de julho de 2002: estabelece diretrizes, critérios e procedimentos para a gestão dos resíduos da construção civil. Diário Oficial da União, Brasília, DF, 17 de julho de 2002.

COUTO NETO, A. G. Construção Civil

Sustentável: avaliação da aplicação do modelo de gerenciamento de resíduos da construção civil do SINDUSCON-MG em um canteiro de obras: um estudo de caso. Belo Horizonte, 2007. $100 \mathrm{f}$. Dissertação (Mestrado em Meio Ambiente, Saneamento e Recursos Hídricos) - Escola de Engenharia, Universidade Federal de Minas Gerais, Belo Horizonte, 2007.

DE MELO, A. B. Gestão dos Resíduos de Construção e Demolição: estudo comparativo Brasil - Portugal. Portugal, 2009. 129 f. Relatório Pós-doutoral (Pós-doutorado em Engenharia Civil) - Laboratório Nacional de Engenharia Civil, Lisboa, Portugal, 2009.

DING, G. K. C. Sustainable Construction: the role of environmental assessment tools. Journal of Environmental Management, v. 86, n. 3, p. 451464, 2008.
FERNANDES, M. P. M. Apreciação de Boas Práticas Visando à Geração de Um Modelo Para Gestão Municipal dos Resíduos da Construção Civil. Porto Alegre, 2013. 264 f. Tese (Doutorado em Engenharia Civil) - Universidade Federal do Rio Grande do Sul, Porto Alegre, 2013.

FORMOSO, C. T. et al. Material Waste in Building Industry: main causes and prevention. Journal of Construction Engineering and Management, v. 128, n. 4, p. 316-325, 2002.

GUERRERO L. A.; MAAS, G.; HOGLAND, W. Solid Waste Management Challenges For Cities in Developing Countries. Journal of Waste Managment, v. 33, n. 1, p. 220-232, 2013. INSTITUTO BRASILEIRO DE GEOGRAFIA E ESTATÍSITCA. Censo 2010. Disponível em: <http://www.censo2010.ibge.gov.br>. Acesso em: 15 mar. 2011.

JAILLON, L.; POON, C. S.; CHIANG, Y. H. Quantifying the waste reduction potential of using prefabrication in building construction in Hong Kong. Journal of Waste Managment, v. 29, n. 1, p. 309-320, 2009.

KOEHN, E.; DATTA, N. K. Quality, Environmental, and Health and Safety Management Systems for Construction Engineering. Journal of Construction Engineering and Management, v. 129, n. 5, p. 562-569, 2003.

LINHARES, S. P.; FERREIRA, J. A.; RITTER, E. Avaliação da Implantação da Resolução n. 307/2002 do CONAMA Sobre Gerenciamento dos Resíduos de Construção Civil. Estudos

Tecnológicos em Engenharia, v. 3, n. 3, p. 176194, out./dez. 2007.

MINISTÉRIO DO TRABALHO E EMPREGO.

NR 7: normas regulamentadoras de saúde e segurança do trabalho. Disponível: <http://portal.mte.gov.br/data/files/FF8080812BE9 14E6012BEF19C09E2799/nr_07_ssst.pdf>. Acesso em: 27 abr. 2015.

\section{MINISTÉRIO DO TRABALHO E EMPREGO.}

NR 9: normas regulamentadoras de saúde e segurança do trabalho. 2014. Disponível em: <http://portal.mte.gov.br/data/files/FF80808148EC 2E5E014961B76D3533A2/NR09\%20(atualizada\%202014)\%20II.pdf >. Acesso em: 08 maio 2015. 
PINTO, T. C. N. O. Sistema de Gestão de Saúde e Segurança no Trabalho: um estudo de caso em usinas de reciclagem de entulho de regiões metropolitanas. São Paulo, 2005. 129 f. Dissertação (Mestrado em Ciências Ambientais) Centro Universitário SENAC, Faculdade de Ciências Ambientais, São Paulo, 2005a.

PINTO, T. C. N. O.; SILVA, M. C. E. S. P. Riscos à Saúde dos Trabalhadores Nos Processos Brasileiros de Reciclagem de Resíduos de Construção e Demolição. Fundação Jorge Duprat Figueiredo de Segurança e Medicina do Trabalho (Fundacentro), São Paulo, 2006. 10 p. Disponível em:

<http://www.segurancaetrabalho.com.br/download /saude-residuos.pdf>. Acesso em: 24 abr. 2015.

PINTO, T. P. et al. Gestão Ambiental de Resíduos da Construção Civil a Experiência do SINDUSCON/SP: cartilha para construtoras. São Paulo: SINDUSCON/SP, São Paulo, 2005. 48 p. Disponível em <www.sindusconsp.com.br>. Acesso em: 24 abr. 2015.

PINTO, T. P. Metodologia Para a Gestão Diferenciada de Resíduos Sólidos da Construção Urbana. São Paulo, 1999. 189 f. Tese (Doutorado em Engenharia Civil) - Escola Politécnica, Universidade de São Paulo, São Paulo, 1999.

POON, C. S. et al. Management of Construction Waste in Public Housing Projects in Hong Kong. Construction Management and Economics, v. 22, n. 7, p. 675-689, 2004.

POON, C. S.; YU, A. T. W.; NG, L. H. On-Site Sorting of Construction and Demolition Waste in Hong Kong. Resources, Conservation and Recycling, v. 32, n. 2, p. 157-172, 2001.

REMBISKI, F. D. Análise Multimétodo de Percepções de Agentes Intervenientes na Pesquisa e no Gerenciamento de Agregados Reciclados de Resíduos da Construção Civil. Vitória, 2012. 246f. Dissertação (Mestrado em Engenharia Civil) - Escola de Engenharia, Universidade Federal do Espírito Santo. Vitória, 2012.

SANTOS, A. M. A.; PINTO, T. C. N. O. Contaminação do Ar em Usinas de Reciclagem Brasileiras e Aspectos de Saúde. Workshop no Dia Mundial de Segurança e Saúde no Trabalho. São Paulo: FUNDACENTRO, 2008. 30 p.
SCHNEIDER, D. M.; PHILIPPI, A. J. Gestão Pública de Resíduos da Construção Civil no Município de São Paulo. Ambiente Construído, Porto Alegre, v. 4, n. 4, p. 21-32, out./dez. 2004.

SEVERINO, A. J. Metodologia do Trabalho Científico. 23. ed. rev. e atual. São Paulo: Cortez, 2007.

SHEN, L. Y. et al. A Checklist For Assessing Sustainability Performance of Construction Projects. Journal of Civil Engineering and Management, v. 13, n. 4, p. 273-281, 2007.

SILVA, M. C. E. P. Sistemas de Gestão de Segurança e Saúde no Trabalho em Usinas de Reciclagem de Entulho: um estudo da exposição ocupacional ao ruído. São Paulo, 2006. 179 f. Dissertação (Mestrado em Sistema Integrado de Gestão em Saúde no Trabalho e Meio Ambiente) Centro Universitário SENAC, São Paulo, 2006.

STAKE. R. E. Case Studies. In: DENZIN, N. K.; LINCOLN, Y. S. (Eds.). Handbook of Qualitative Research. London: Sage, 2000.

TAM, V. W. Y.; TAM, C. M. A Review on the Viable Technology For Construction Waste Recycling. Resources, Conservation and Recycling, v. 47, n. 3, p. 209-221, 2006.

TESSARO, A. B.; SÁ, J. S.; SCREMIN, L. B. Quantificação e Classificação dos Resíduos Procedentes da Construção Civil e Demolição no Município de Pelotas, RS. Ambiente Construído, Porto Alegre, v. 12, n. 2, p. 121-130, abr./jun. 2012.

YEHEYIS, M. et al. An Overview of Construction and Demolition Waste Management in Canada: a lifecycle analysis approach to sustainability. Clean Technology \& Environmental Policy, v. 15, n. 1, p. 81-91, 2013.

YIN, R. K. Case Study Research: design end methods. 4. ed. New York: Sage Inc. Publications, 2009. v. 5, 216 p. Applied Social Research Method Series.

\section{Agradecimentos}

À SLU, pelas informações fornecidas e pelo livre acesso da pesquisadora aos locais requeridos para a coleta de dados. A todos os trabalhadores que voluntariamente participaram da pesquisa, partilhando sua experiência e suas expectativas.

À Capes. 


\section{Maria da Paz Medeiros Fernandes}

Unidade Acadêmica de Gestão | Instituto Federal de Educação, Ciência e Tecnologia da Paraíba | Av. Primeiro de Maio, 720, Jaguaribe | João Pessoa - PB - Brasil | CEP 58015-430 | Tel.: (83) 3612-1200 | E-mail: pazmedeiros@bol.com.br

\section{Luiz Carlos Pinto da Silva Filho}

Departamento de Engenharia Civil, Escola de Engenharia | Universidade Federal do Rio Grande do Sul | Av. Osvaldo Aranha, $99,7^{\circ}$ andar, Centro | Porto Alegre - RS - Brasil | CEP 90035-190 | Tel.: (51) 3308-3489 | E-mail: Icarlos66@gmail.com

\section{Revista Ambiente Construído}

Associação Nacional de Tecnologia do Ambiente Construído

Av. Osvaldo Aranha, $99-3^{\circ}$ andar, Centro

Porto Alegre - RS - Brasil

CEP $90035-190$

Telefone: +55 (51) 3308-4084

Fax: +55 (51) 3308-4054

www.seer.ufrgs.br/ambienteconstruido

E-mail: ambienteconstruido@ufrgs.br 